\title{
Comparative study of absorption band edge tailoring by cationic and anionic doping in $\mathrm{TiO}_{2}$
}

\author{
Arpit Swarup MATHur ${ }^{1 *}$, PrAVEen KUMAR $^{2}$, B.P. Singh ${ }^{1}$ \\ ${ }^{1}$ Department of Physics, Institute of Basic Sciences, Dr. B.R. Ambedkar University, Khandari, Agra-282002 U.P., India \\ ${ }^{2}$ Dau Dayal Institute of Vocational Education, Dr. B.R. Ambedkar University, Khandari, Agra-282002 U.P., India
}

\begin{abstract}
Titanium dioxide $\left(\mathrm{TiO}_{2}\right)$ is one of the most favored metal oxide semiconductors for the use as photoanode in photoelectrochemical cells (PEC) splitting the water into hydrogen and oxygen. However, the major impediment is its large bandgap that limits its utilization as photoanode. Doping has evolved as an effective strategy for tailoring optical and electronic properties of $\mathrm{TiO}_{2}$. This paper describes the synthesis of undoped as well as iron (Fe, cationic) and nitrogen (N, anionic) doped nanocrystalline titanium dioxide by sol-gel spin coating method for solar energy absorption in the visible region. All the prepared thin films were characterized by X-ray diffraction and UV-Vis spectroscopy. Doping of both Fe and $\mathrm{N}$ into $\mathrm{TiO}_{2}$ resulted in a shift of absorption band edge towards the visible region of solar spectrum.
\end{abstract}

Keywords: nanocrystal; titanium dioxide; doping; iron; nitrogen; thin films

\section{Introduction}

Titanium dioxide $\left(\mathrm{TiO}_{2}\right)$ is a transition metal oxide that occurs in three different natural forms (rutile, anatase, and brookite) as well as in five polymorphs that can be synthetically prepared [13]. Anatase $\mathrm{TiO}_{2}$ has been investigated as a functional ceramics for a wide variety of applications, such as solar cells, anode materials in batteries, ceramics, photocatalysis, protective coatings, antireflection coatings, and optoelectronics [4-8]. It is one of the few materials that have suitable band edge positions for water splitting applications, without any need of an external bias. The conduction and valence band edges of $\mathrm{TiO}_{2}$ match with the redox level of water. This facilitates easy transfer of charge carriers at semiconductor/electrolyte junction in PEC cell. However, photoresponse of $\mathrm{TiO}_{2}$ is limited due to its large bandgap $\sim 3.2 \mathrm{eV}$. This bandgap is capable of absorbing only $\sim 4 \%$ of incoming solar radiation [9]. Due to its large bandgap, it absorbs only the ultraviolet part of the solar spectrum.

*E-mail: arpitswarupmathur@gmail.com
Doping is one of the most fruitful approaches for tailoring the band gap of $\mathrm{TiO}_{2}$ in visible regime to enhance its PEC response. Doping produces impurity states in the band gap of semiconductor to enhance visible-light absorption as well as to ensure its photoreduction activity [10]. A lot of research has been done on doping of $\mathrm{TiO}_{2}$ with various metal ions, such as iron and copper [11-15], or non-metal species, such as silicon $[16,17]$, nitrogen [18, 19], phosphorus [20], carbon [21, 22], sulfur [23], boron [24], and halides [25].

Among various cationic/anionic dopants, substitution of iron (III) ions in the titania lattice is most favored [26] due to similar size of $\mathrm{Fe}^{3+}$ and $\mathrm{Ti}^{4+}$ ions. However, in N-doping, under optimal conditions, oxygen atoms in the $\mathrm{TiO}_{2}$ lattice are substituted with nitrogen ions, thus, the corresponding $N(2 p)$ states are located above the valence band edge. In other words, mixing of $N(2 p)$ states with $\mathrm{O}(2 \mathrm{p})$ states can take place, and the narrowing of the band gap occurs. This leads to higher photoresponse of doped $\mathrm{TiO}_{2}$ samples under visible light irradiation.

In the present study, thin films of undoped $\mathrm{TiO}_{2}$, Fe doped $\mathrm{TiO}_{2}$ and $\mathrm{N}$-doped $\mathrm{TiO}_{2}$ have been 
prepared by simple, economical, sol-gel spin coating technique. The effect of doping has been studied with respect to absorption band edge.

\section{Experimental}

Titanium tetraisopropoxide (TTIP), ethanol, diethanolamine, iron nitrate and aqueous ammonia solution were used as received from SigmaAldrich, for the preparation of the sol-gel. Tin doped indium oxide (ITO) substrates were used for thin film deposition because of their electrical conductivity and optical transparency. Also, the thin films can be deposited over it easily.

A transparent gel solution of undoped/Fe doped titanium dioxide was prepared by mixing $3 \mathrm{~mL}$ TTIP and appropriate amount of iron nitrate (0.1 at.\%, 0.2 at.\%, 0.5 at.\% and 1.0 at.\%) in $20 \mathrm{~mL}$ ethanol in the presence of diethanolamine. The solution was stirred for $4 \mathrm{~h}$ at room temperature to enhance the reaction rate between diethanolamine and TTIP which finally converted into gel. Doping concentration was varied from 0.1 at.\% to 1.0 at. $\% \mathrm{Fe}$.

For N-doped $\mathrm{TiO}_{2}, 25 \mathrm{~mL}$ of aqueous ammonia solution was added slowly dropwise to $10 \mathrm{~mL}$ of titanium tetraisopropoxide with continuous stirring in an ice bath. Concentration of ammonia was varied from $15 \%$ to $25 \%$ to obtain various doping levels of nitrogen in $\mathrm{TiO}_{2}$. For undoped $\mathrm{TiO}_{2}$, the ammonia solution was replaced by double distilled water. White precipitated solution was obtained after ultrasonication and stirring for $2 \mathrm{~h}$.

Few drops of prepared gel (cationic as well as anionic doping) were dropped over the substrate and the substrate was rotated at the speed of $3000 \mathrm{rpm}$ for $30 \mathrm{~s}$. Six such layers of films were deposited after heating each consecutive layer for about $2 \mathrm{~min}$ at $60{ }^{\circ} \mathrm{C}$. The substrates were brought back to room temperature before deposition of every next layer. Final sintering was done in a microprocessor controlled electric furnace (MF-9M, Metrex Scientific Instruments (P) Ltd., New Delhi) at $500{ }^{\circ} \mathrm{C}$ for $2 \mathrm{~h}$. All the prepared thin films were characterized by UV-Vis spectroscopy and X-ray diffractometry for absorption band edge determination and phase determination, respectively.

\section{Results and discussion}

\subsection{Optical characterization}

UV-Vis spectra clearly indicate red shift in absorption band edge upon introduction of $\mathrm{Fe}^{3+}$ ions into $\mathrm{TiO}_{2}$ as shown in Fig. 1. Absorption band edge for undoped $\mathrm{TiO}_{2}$ has been found to be $371 \mathrm{~nm}$ corresponding to band edge energy change of $3.3 \mathrm{eV}$. Introduction of $\mathrm{Fe}$ in $\mathrm{TiO}_{2}$ has led to red shift in absorption band edge for all $\mathrm{Fe}$ doped samples as compared to undoped $\mathrm{TiO}_{2}$ sample. The maximum shift in the band edge energy, from $371 \mathrm{~nm}$ to $465 \mathrm{~nm}$, has been observed for 0.2 at.\% Fe doped $\mathrm{TiO}_{2}$, corresponding to band edge energy change of $3.3 \mathrm{eV}$ to $2.67 \mathrm{eV}$, respectively. The red shift in absorption band edge may be attributed to the creation of intermediate energy levels due to Fe doping as $\mathrm{Fe}^{3+} / \mathrm{Fe}^{2+}$ energy level lies just below the conduction band of $\mathrm{TiO}_{2}$ and $\mathrm{Fe}^{3+} / \mathrm{Fe}^{4+}$ level lies just above the valence band of $\mathrm{TiO}_{2}$, making it a temporary trapping site for photogenerated charge carriers prolonging their recombination time, so that captured electrons or holes can be easily released from $\mathrm{Fe}^{2+}$ or $\mathrm{Fe}^{4+}$ to regenerate $\mathrm{Fe}^{3+}$ [27]

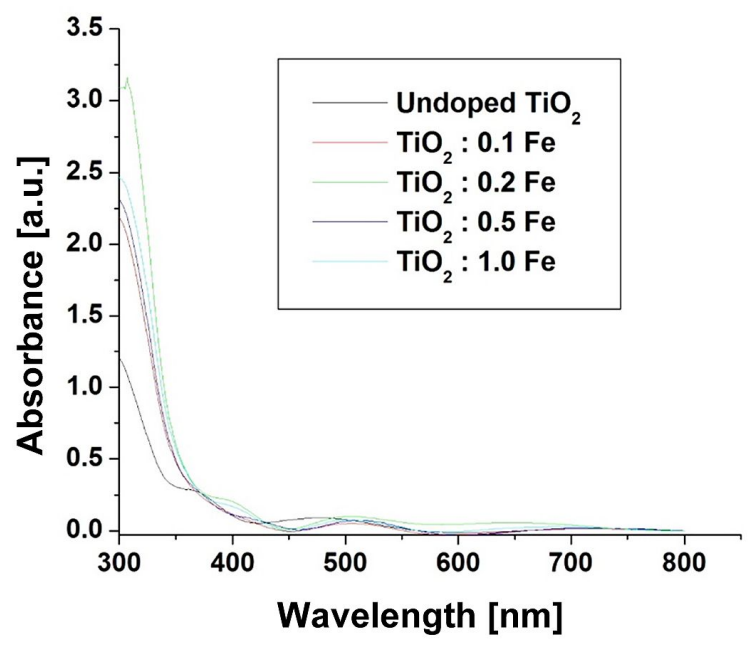

Fig. 1. Absorption spectra of undoped and Fe doped $\mathrm{TiO}_{2}$ thin films.

Similarly, in the case of $\mathrm{N}$-doped $\mathrm{TiO}_{2}$, all the doped samples exhibited red shift in the absorption band edge energy as compared to undoped $\mathrm{TiO}_{2}$ sample as shown in Fig. 2. The absorption 
Table 1. Optical properties of $\mathrm{Fe}$ and $\mathrm{N}$-doped $\mathrm{TiO}_{2}$ samples.

\begin{tabular}{|c|c|c|c|c|c|}
\hline \multicolumn{3}{|c|}{ Fe doped $\mathrm{TiO}_{2}$ sample } & \multicolumn{3}{|c|}{$\mathrm{N}$-doped $\mathrm{TiO}_{2}$ sample } \\
\hline Sample ID & $\begin{array}{c}\text { Absorption } \\
\text { band edge } \\
{[\mathrm{nm}]}\end{array}$ & $\begin{array}{l}\text { Corresponding } \\
\text { band edge } \\
\text { energy }[\mathrm{eV}]\end{array}$ & Sample ID & $\begin{array}{l}\text { Absorption } \\
\text { band edge } \\
{[\mathrm{nm}]}\end{array}$ & $\begin{array}{l}\text { Corresponding } \\
\text { band edge } \\
\text { energy }[\mathrm{eV}]\end{array}$ \\
\hline Undoped $\mathrm{TiO}_{2}$ & 371 & 3.3 & Undoped $\mathrm{TiO}_{2}$ & 371 & 3.3 \\
\hline $\mathrm{TiO}_{2}: 0.1 \mathrm{Fe}$ & 423 & 2.94 & $\mathrm{TiO}_{2}: 15 \% \mathrm{NH}_{3}$ & 443 & 2.81 \\
\hline $\mathrm{TiO}_{2}: 0.2 \mathrm{Fe}$ & 465 & 2.67 & $\mathrm{TiO}_{2}: 20 \% \mathrm{NH}_{3}$ & 448 & 2.77 \\
\hline $\mathrm{TiO}_{2}: 0.5 \mathrm{Fe}$ & 416 & 2.98 & $\mathrm{TiO}_{2}: 25 \% \mathrm{NH}_{3}$ & 570 & 2.18 \\
\hline $\mathrm{TiO}_{2}: 1.0 \mathrm{Fe}$ & 408 & 3.04 & - & - & - \\
\hline
\end{tabular}

band edge shifts from $371 \mathrm{~nm}$ for undoped $\mathrm{TiO}_{2}$ to $570 \mathrm{~nm}$ for $25 \% \mathrm{NH}_{3}$ doped sample corresponding to band edge energy of $2.18 \mathrm{eV}$ and $3.3 \mathrm{eV}$, respectively. The shift in absorption band edge energy may be due to the replacement of oxygen sites by nitrogen atoms during synthesis of $\mathrm{TiO}_{2}$ films using $\mathrm{NH}_{3}$ [28]. Absorption band edges and corresponding energies have been tabulated in Table 1.

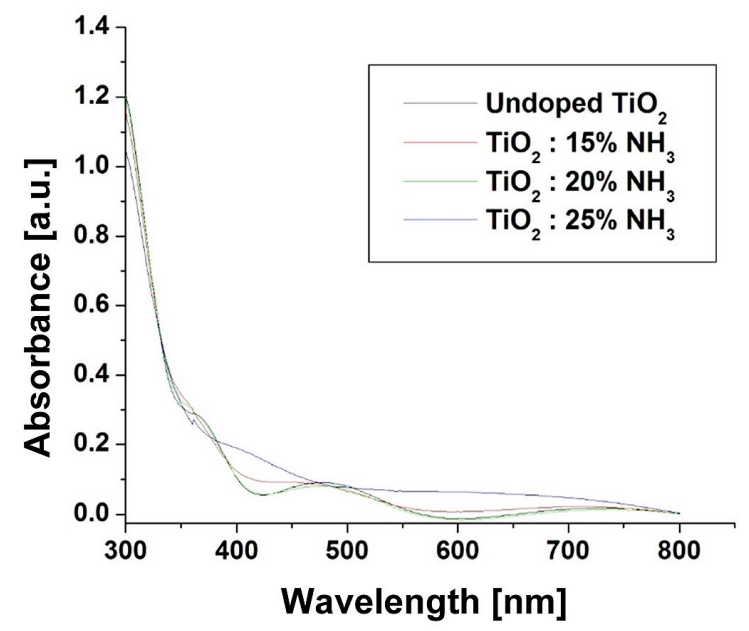

Fig. 2. Absorption spectra of undoped and N-doped $\mathrm{TiO}_{2}$.

\subsection{Phase determination}

All of the prepared $\mathrm{Fe}$ and $\mathrm{N}$-doped $\mathrm{TiO}_{2}$ samples exhibited features characteristic of an anatase $\mathrm{TiO}_{2}$ crystallographic phase. Peaks were observed at $2 \theta=25.28^{\circ}, 37.8^{\circ}, 48.04^{\circ}, 53.89^{\circ}$ corresponding to (llll $\left.\begin{array}{lll}0 & 1\end{array}\right),\left(\begin{array}{lll}0 & 0 & 4\end{array}\right),\left(\begin{array}{lll}2 & 0 & 0\end{array}\right)$ and $\left(\begin{array}{lll}1 & 0 & 5\end{array}\right)$ anatase phases of $\mathrm{TiO}_{2}$ (JCPDS Card No. 21-1272) [29] as shown in Fig. 3. The anatase phase has been retained without transformation to any other phase, even after increasing the doping concentration of iron or ammonia solution. XRD pattern shows that any other phase has not been observed. Also, no evidence of presence of iron or nitrogen was revealed which may be attributed to the presence of low amount of these elements in the $\mathrm{TiO}_{2}$ matrix.

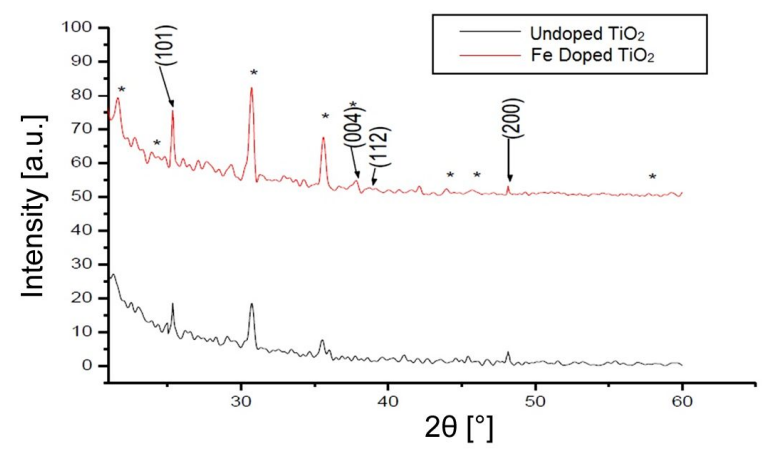

Fig. 3. XRD patterns for undoped and $\mathrm{Fe}$ doped $\mathrm{TiO}_{2}$.

\section{Conclusions}

Doped $\mathrm{TiO}_{2}$ nanostructured thin films have appeared as superior candidates for its future utilization as photoanodes in a PEC cell. Both Fe and $\mathrm{N}$-doping in $\mathrm{TiO}_{2}$ led to a reduction in the absorption band edge energy as compared to the pristine $\mathrm{TiO}_{2}$ sample. 0.2 at. $\% \mathrm{Fe}$ doped $\mathrm{TiO}_{2}$ sample showed a band edge shift from $371 \mathrm{~nm}$ of undoped to $465 \mathrm{~nm}$, corresponding to $3.3 \mathrm{eV}$ to $2.67 \mathrm{eV}$, respectively. Also, $25 \% \mathrm{NH}_{3}$ treated 
$\mathrm{TiO}_{2}$ sample exhibited an absorption band edge shift from $371 \mathrm{~nm}$ of undoped to $570 \mathrm{~nm}$ as compared to $3.3 \mathrm{eV}$ and $2.18 \mathrm{eV}$, respectively. Both these doped $\mathrm{TiO}_{2}$ samples proved to be a fruitful step in the direction of improving the suitability of $\mathrm{TiO}_{2}$ as a promising material for solar generation of hydrogen.

The band edge shifting may be due to the additional states created in the crystal structure of $\mathrm{TiO}_{2}$ by doping [30, 31]. $\mathrm{N}$-doping causes more shift in absorption band edge towards visible region than $\mathrm{Fe}$ doping, which suggests that $\mathrm{N}$-doping is more effective in $\mathrm{TiO}_{2}$ for band gap narrowing as compared to $\mathrm{Fe}$ doping in $\mathrm{TiO}_{2}$. Also, in case of $\mathrm{N}$-doping, more shifting in the band edge may be due to the defects associated with oxygen vacancies that give rise to color centers [32].

\section{Acknowledgements}

We are highly thankful to Prof. Vibha R. Satsangi, and research scholars, Dr. Snigdha Rai and Dr. Ashi Ikram, of Nanostructured Semiconductor Laboratory, Department of Physics and Computer Science, Dayalbagh Educational Institute, Agra, for providing synthesis and characterization facilities and helping in data analysis.

\section{References}

[1] Hu Y., Tsai H.L., HuangK C.L., Eur. Ceram. Soc., 23 (2003), 691.

[2] Shao Y., Tang D., Sun J., LeE Y., Xiong W., China Particuology, 2 (2004), 119.

[3] Kaczmarek D., Prociow E. L., Domaradzki J., Borkowska A., MielcareK W., WoJCIESZAK D., Mater. Sci.-Poland, 26 (1) (2008), 113.

[4] Chambers S.A., Thevuthasan S., Farrow R.F.C., Marks R.F., Thiele J.U., Folks L., Appl. Phys. Lett., 79 (2001), 3467.

[5] Kumazawa N., Islam M. R., Takeuchi M., J. Electrochem. Chem., 472 (1999), 137.

[6] Ohko Y., Tatsuma T., Fujil T., Naoi K., Niwa C., Kubata Y., Fujishima A., Nat. Mater., 2 (2003), 29.

[7] Gao X., Zhu H., Pan G., Ye S., Lan Y., Wu F., Song D., J. Phys. Chem. B, 108 (2004), 2868.

[8] Wang Y.G., Wang Z.D., XIA Y.Y., Electrochim. Acta, 50 (2005), 5641.

[9] Fahmi A., Minot C., Silvi B., Causa M., Phys. Rev. B, 47 (1993), 11717.

[10] ZaleskA A., Recent Pat. Eng., 2 (2008),157.
[11] BaK T., Nowotny J., Rekas M., Sorrell C.C., Int. J. Hydrogen Energ., 27 (2002), 991.

[12] Choi W.Y., Termin A., Hoffmann M. R., J. Phys. Chem., 98 (1994), 13669.

[13] Anpo M., Matsuoka M., Mishima H., YaMASHITA H., Res. Chem. Intermediat., 23 (1997), 197.

[14] Ghosh A.K., Maruska H.P., J. Electrochem. Soc., 124 (1977), 1516.

[15] Ingler W.B., KHAN S.U.M., Int. J. Hydrogen Energ., 30 (2005), 821.

[16] Yarahmadi S.S., WiJayantha K.G.U., TAhiR A.A., Vaidhyanathan B., J. Phys. Chem. C, 113 (2009), 4768.

[17] Mohapatra S.K., Mahajan V.K., Misra M., Nanotechnology, 18 (2007), 445705.

[18] Yan Y., Ahn K.S., Shet S., Deutsch T., Huda M., Wei S.H., Turner J., Al-Jassim M.M., Proc. SPIE, 6650 (2007), 66500H.

[19] Cui X., Ma M., Zhang W., Yang Y.C., Zhang Z.H., Electrochem. Commun., 10 (2008), 367.

[20] Lin L., Lin W., ZhU Y.X., ZhaO B.Y., Xie Y.C., Chem. Lett., 34 (2005), 284.

[21] XU C.K., Shaban Y.A., Ingler W.B., Khan S.U.M., Sol. Energ. Mat. Sol. C., 91 (2007), 938.

[22] Sakthivel S., Kisch H., Angew. Chem. Int. Edit., 42 (2003), 4908.

[23] Ohno T., Mitsui T., Matsumura M., Chem. Lett., 32 (2003), 364.

[24] Zhao W., Ma W.H., Chen C.C., Zhao J.C., Shuai Z.G., J. Am. Chem. Soc., 126 (2004), 4782.

[25] Luo H.M., TAKata T., LEE Y.G., ZHaO J.F., Domen K., Yan Y.S., Chem. Mater., 16 (2004), 846.

[26] Choi W., Termin A., Hoffmann M.R., J. Phys.Chem., 98 (1994), 13669.

[27] Ranjit K.T., Viswanathan B., J. Photochem. Photobiol. A, 108 (2007), 79.

[28] Shin C.H., Bugli G., DJega-Mariadassou G., $J$. Solid State Chem., 95 (1991), 145.

[29] PONGWAN P., INCEESUNGVORN B. WETCHAKUN K., PHANICHPHANT S., WETCHAKUn N., Eng. J., 16 (3) (2012), 143.

[30] Singh A.P., Kumari S., Sonal, Shrivastav R., Dass S., Satsangi V.R., J. Sci. Conf. Proc., 1 (2009), 82.

[31] Singh A.P., Kumari S., Shrivastav R., Dass S., SAtsangi V.R., Int. J. Hydrogen Energ., 33 (2008), 5363.

[32] Serpone N., J. Phys. Chem. B, 110 (2006), 24287. 